Article

\title{
Simple Synthesis of Red Iridium(III) Complexes with Sulfur-Contained Four-Membered Ancillary Ligands for OLEDs
}

\author{
Meng-Xi Mao ${ }^{1}$ (D), Fang-Ling Li ${ }^{1}$, Yan Shen ${ }^{1}$, Qi-Ming Liu ${ }^{1}$, Shuai Xing ${ }^{1}$, Xu-Feng Luo ${ }^{1}$, Zhen-Long Tu ${ }^{1}$, \\ Xue-Jun $\mathrm{Wu}^{1}$ and You-Xuan Zheng ${ }^{1,2, *}$
}

\section{check for}

updates

Citation: Mao, M.-X.; Li, F.-L.; Shen, Y.; Liu, Q.-M.; Xing, S.; Luo, X.-F.; Tu, Z.-L.; Wu, X.-J.; Zheng, Y.-X. Simple Synthesis of Red Iridium(III)

Complexes with Sulfur-Contained Four-Membered Ancillary Ligands for OLEDs. Molecules 2021, 26, 2599. https://doi.org/10.3390/ molecules26092599

Academic Editors: Guohua Xie Chien-Jung Huang and Kuan-Wei Lee

Received: 2 April 2021

Accepted: 27 April 2021

Published: 29 April 2021

Publisher's Note: MDPI stays neutra with regard to jurisdictional claims in published maps and institutional affiliations.

Copyright: (c) 2021 by the authors. Licensee MDPI, Basel, Switzerland. This article is an open access article distributed under the terms and conditions of the Creative Commons Attribution (CC BY) license (https:// creativecommons.org/licenses/by/ $4.0 /)$.
1 State Key Laboratory of Coordination Chemistry, Collaborative Innovation Center of Advanced Microstructures, Jiangsu Key Laboratory of Advanced Organic Materials, School of Chemistry and Chemical Engineering, Nanjing University, Nanjing 210023, China; mf1924021@smail.nju.edu.cn (M.-X.M.); mg1824034@smail.nju.edu.cn (F.-L.L.); mf1824030@smail.nju.edu.cn (Y.S.); 171850043@smail.nju.edu.cn (Q.-M.L.); mf20240035@smail.nju.edu.cn (S.X.); dg1924062@smail.nju.edu.cn (X.-F.L.); dg1824074@smail.nju.edu.cn (Z.-L.T.); xjwu@nju.edu.cn (X.-J.W.)

2 Green Catalysis Center and College of Chemistry, Zhengzhou University, Zhengzhou 450001, China

* Correspondence: yxzheng@nju.edu.cn

\begin{abstract}
Phosphorescent iridium(III) complexes have been widely researched for the fabrication of efficient organic light-emitting diodes (OLEDs). In this work, three red Ir(III) complexes named Ir-1, Ir-2, and Ir-3, with Ir-S-C-S four-membered framework rings, were synthesized efficiently at room temperature within 5 min using sulfur-containing ancillary ligands with electron-donating groups of 9,10-dihydro-9,9-dimethylacridine, phenoxazine, and phenothiazine, respectively. Due to the same main ligand of 4-(4-(trifluoromethyl)phenyl)quinazoline, all Ir(III) complexes showed similar photoluminescence emissions at 622,619 , and $622 \mathrm{~nm}$ with phosphorescence quantum yields of $35.4 \%$, $50.4 \%$, and $52.8 \%$, respectively. OLEDs employing these complexes as emitters with the structure of ITO (indium tin oxide)/HAT-CN (dipyra-zino[2,3-f,2', $3^{\prime}$-h] quinoxaline-2,3,6,7,10,11-hexacarbonitrile, $5 \mathrm{~nm}) /$ TAPC $\left(4,4^{\prime}\right.$-cyclohexylidenebis[N,N-bis-(4-methylphenyl)aniline], $\left.40 \mathrm{~nm}\right) / \mathrm{TCTA}\left(4,4^{\prime \prime}, 4^{\prime \prime}\right.$ tris(carbazol-9-yl)triphenylamine, $10 \mathrm{~nm}$ )/ Ir(III) complex (10 wt\%): 2,6DCzPPy (2,6-bis-(3-(carbazol9-yl)phenyl)pyridine, $10 \mathrm{~nm}$ )/TmPyPB (1,3,5-tri(mpyrid-3-yl-phenyl)benzene, $50 \mathrm{~nm}$ )/LiF (1 nm)/Al $(100 \mathrm{~nm})$ achieved good performance. In particular, the device based on complex Ir-3 with the phenothiazine unit showed the best performance with a maximum brightness of $22,480 \mathrm{~cd} \mathrm{~m}^{-2}$, a maximum current efficiency of $23.71 \mathrm{~cd} \mathrm{~A}^{-1}$, and a maximum external quantum efficiency of $18.1 \%$. The research results suggest the $\mathrm{Ir}(\mathrm{III})$ complexes with a four-membered ring Ir-S-C-S backbone provide ideas for the rapid preparation of Ir(III) complexes for OLEDs.
\end{abstract}

Keywords: red iridium(III) complex; Ir-S-C-S four-membered backbone; fast synthesis; OLED

\section{Introduction}

Since the innovative work in 1997 by C. W. Tang, organic light-emitting diodes (OLEDs) have been rapidly developed for decades [1]. Among them, phosphorescent OLEDs incorporating phosphorescent transition metal complexes such as iridium(III) or platinum(II) have attracted considerable attention from both academic and industrial communities, which is due to their superior efficiency, low turn-on voltage, and vibrant color tunability [2]. Introducing the central heavy atom in luminescent complexes can result in strong spin-orbit coupling (SOC), which would promote a triplet to ground radiative transition, harvesting both singlet/triplet excitons and leading to a quite high phosphorescence quantum efficiency [3,4]. Thus, a great deal of effort has been spent inquiring into the third-row transition-metal complexes to develop phosphorescent OLEDs with improving device performances [5]. In particular, the Ir(III) complexes with diverse ligands are by far the 
most effective heavy metal complexes of triplet emitters for phosphorescent OLEDs due to the relative short excited lifetime and high efficiency $[6,7]$.

However, in most cases, the ancillary ligands of $\operatorname{Ir}(\mathrm{III})$ complexes mainly rely on six- or five-membered ring structures such as acetylacetonate (acac), picolinate (pic), and tetraphenylimidodiphosphinate [8]. Four-membered ancillary ligands are rarely researched because the conventional idea believes that the materials containing four-membered rings are not stable. The four-membered metal-ligand frame can shorten the distance between the metal center and ligand, so the MLCT (metal-to-ligand charge transfer) progress can be promoted. Therefore, it is a hopeful way to synthesize superior Ir(III) complexes by using four-membered ring ligands, which are beneficial to enhancing the photoluminescence (PL) quantum efficiency [9].

As a $\mathrm{d}^{6}$ metal, an iridium atom can form an octahedral coordination configuration in a trivalent form, and the key ligands in the Ir(III) complex generally coordinate to the metal center via the formation of Ir-N and Ir-C bonds $[6,10]$. The $\mathrm{S}$ atom has a high affinity and good coordination ability for transition metal ions, which can lead to the synthesis of Ir(III) complexes with sulfur-containing ligands at room temperature [11,12]. Besides, the sulfur atom is able to stabilize metal ions in unusual oxidation states [13-15]. Therefore, it has a great advantage over the costly traditional way of refluxing the $\left[\left(\mathrm{C}^{\wedge} \mathrm{N}\right)_{2} \operatorname{Ir}(\mu-\mathrm{Cl})\right]_{2}$ chloride-bridged dimers with cyclometalated or ancillary ligands at high temperature for a long time [16].

There are only a few examples of $\operatorname{Ir}(\mathrm{III})$ complexes with Ir-S-C-S structures and most of them are based on $N, N^{\prime}$-diehyldithiocarbamate $\left(\mathrm{Et}_{2} \mathrm{dtc}\right)$ ancillary ligands. In 2005, Yang et al. first reported an $\operatorname{Ir}(\mathrm{III})$ (ppy) ${ }_{2} \operatorname{Ir}\left(\mathrm{Et}_{2} \mathrm{dtc}\right)$ complex with a four-membered Ir-S-C-S structure [17]. Immediately afterwards, they reported more four-membered $\operatorname{Ir}(\mathrm{III}) \mathrm{com}-$ plexes, and the device based on a blue Ir(III) complex with a 1,3,4-oxadiazole derivative as cyclometalated ligand showed a maximum current efficiency $\left(\eta_{\mathrm{c}, \max }\right)$ of $9.88 \mathrm{~cd} \mathrm{~A}^{-1}[18,19]$. In 2016, Mei et al. reported an orange-emitting complex $\operatorname{Ir}(\mathrm{dpp})_{2}(\mathrm{dta})$ with diethyldithiocarbamate (dta) as the ancillary ligand, and its device achieved a maximum external quantum efficiency (EQE $E_{\max }$ ) of $9.28 \%$ [20]. However, they prepared the $\operatorname{Ir}(\mathrm{III})$ complexes with the traditional method and the device performances should be improved. In our former study, we prepared some red Ir(III) complexes using 4-(4-(trifluoromethyl)phenyl)quinazoline (4tfmpq) as the cyclometalated ligand. Diisopropylamine, diphenylamine, carbazole and their derivatives substituted dithiocarbamates as ancillary ligands at room temperature within $10 \mathrm{~min}$, and the device performances were improved greatly [16,21,22]. Furthermore, from our investigation we found that the Ir-S-C-S structures were only valuable for the red $\operatorname{Ir}(\mathrm{III})$ complexes with excellent device performance.

With the above consideration, three four-membered red Ir(III) complexes with sulfur atom-containing dithiocarbamate derivatives as ancillary ligands constructed with different electron-donating groups of 9,10-dihydro-9,9-dimethylacridine, phenoxazine, and phenothiazine were synthesized with a $\left[(4 \mathrm{tfmpq})_{2} \operatorname{Ir}(\mu-\mathrm{Cl})\right]_{2}$ dimer at room temperature within $5 \mathrm{~min}$. The bulky trifluoromethyl groups efficiently depressed the molecular packing and triplet-triplet annihilation (TTA) effect, and the low vibrational frequency of the C-F bond reduced the nonradiative transition rate. In addition, the nitrogen heterocycle also promoted the electron mobility of the $\operatorname{Ir}(\mathrm{III})$ complexes, thus enhancing the electron-hole injection balance. Therefore, the bipolar properties of the $\operatorname{Ir}(\mathrm{III})$ complexes are beneficial for their OLED performance with reduced efficiency roll-off [3].

\section{Results and Discussion}

\subsection{Preparation and Characterization}

The chemical structures and synthetic routes of three Ir(III) complexes are showed in Scheme 1. The synthesized main ligand $4 \mathrm{tfmpq}$ via a Suzuki coupling reaction reacted with $\mathrm{IrCl}_{3} \cdot \mathrm{nH}_{2} \mathrm{O}$ to obtain the $\left[(4 \mathrm{tfmpq})_{2} \mathrm{Ir}(\mu-\mathrm{Cl})\right]_{2}$ dimer. Three $\mathrm{S}$ atom-containing ligand salts were synthesized by the reaction of 9,10-dihydro-9,9-dimethylacridine, phenoxazine, or phenothiazine with $\mathrm{NaH}$ and $\mathrm{CS}_{2}$. Due to the sensitivity to water and oxygen, the 
ancillary ligands were used directly without further purification [23]. Remarkably, all the Ir(III) complexes were prepared under quite mild conditions (5 $\mathrm{min}$ at room temperature in tetrahydrofuran) in yields of $48.9-85.5 \%$, owing to the strong coordination capability of sulfur atoms with iridium atoms [24]. All these complexes were characterized by ${ }^{1} \mathrm{H} N M R$, ${ }^{13} \mathrm{C}$ NMR, ${ }^{9} \mathrm{~F}$ NMR, and high-resolution mass spectrometer (HR-MS). Particularly, the single crystals of Ir- 2 and Ir-3 were obtained by growing slowly through solvent diffusion from methanol into dichloromethane solutions at room temperature.<smiles>Cc1ccc([Hg]O)cc1</smiles><smiles>Clc1ncnc2ccccc12</smiles><smiles>CC(C)(F)c1ccc(-c2ncnc3ccccc23)cc1</smiles><smiles>C1=CCCCC1</smiles>

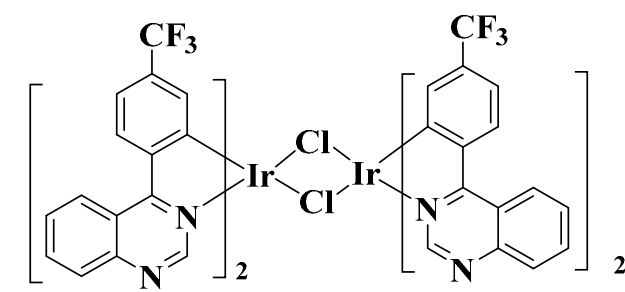

$\left[(4 \mathrm{tfmpq})_{2} \operatorname{Ir}(\mu-\mathrm{Cl})\right]_{2}$<smiles>CC1(C)c2ccccc2Nc2ccccc2C1(C)c1cc2ccccc2n1C(=S)[Sn]</smiles><smiles>c1ccc2c(c1)Nc1ccccc1O2</smiles><smiles>C1CCCCC1</smiles><smiles>S=C([S-])N1c2ccccc2Oc2ccccc21</smiles><smiles>[CH]=C</smiles>

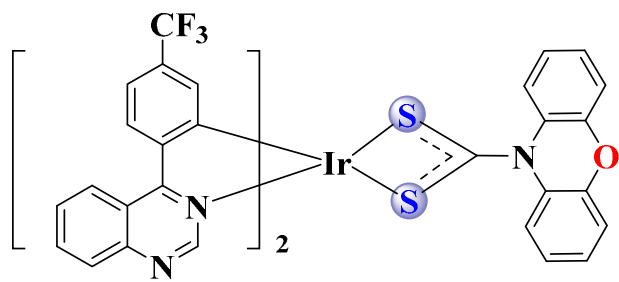

Ir-2<smiles>CC1(C)CCCCC1</smiles><smiles>S=C([S-])N1c2ccccc2Sc2ccccc21</smiles>

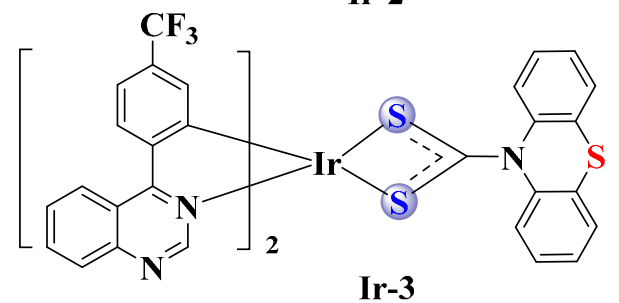

(a) $\mathrm{Pd}\left(\mathrm{PPh}_{3}\right)_{4}, \mathrm{Na}_{2} \mathrm{CO}_{3}, \mathrm{THF}-\mathrm{H}_{2} \mathrm{O}, 70^{\circ} \mathrm{C}, 12 \mathrm{~h}$

(c) $\mathrm{NaH}, \mathrm{CS}_{2}$, THF, R.T., 3 h (b) $\mathrm{IrCl}_{3}, \mathrm{EtOCH}_{2} \mathrm{CH}_{2} \mathrm{OH}-\mathrm{H}_{2} \mathrm{O}, 115^{\circ} \mathrm{C}, 12 \mathrm{~h}$

(d) $\left[(4 \mathrm{tfmpq})_{2} \operatorname{Ir}(\mu-\mathrm{Cl})\right]_{2}$, THF, R.T., 5 min

Scheme 1. Synthesis routes of the ligands and $\operatorname{Ir}(\mathrm{III})$ complexes.

The single-crystal structures of Ir-2 and Ir-3 were further proved by X-ray crystallography (Figure 1), and the crystallographic data and the selected important bond lengths/angles are summarized in Tables S1 and S2, respectively. It is obvious that the metal iridium atom center exhibited a distorted three-dimensional octahedral coordination geometry with an $\mathrm{S}^{\wedge} \mathrm{S}$ ancillary ligand and two $\mathrm{C}^{\wedge} \mathrm{N}$ cyclometalated ligands. Both the phenothiazine ring and phenoxazine ring showed a nonplanar butterfly conformation, whereas the phenothiazine group formed a larger bend with the Ir-S-C-S plane than with the phenoxazine group. The quinazoline core framework showed a certain angle related to the adjacent 4-trifluoromethyl-phenyl unit, which was due to the steric hindrance orig- 
inating from the through-space repulsion between the two nearby hydrogen atoms [25]. The similarity of bond lengths of S1-O3 (1.716(7) $\AA$ for Ir-2, 1.699(4) $\AA$ for Ir-3) and S2-O3 (1.708(7) $\AA$ for Ir-2, 1.706(4) $\AA$ for Ir-3) indicates that the -1 charge of the dithiocarbamate was delocalized over both sulfur atoms [26]. The four-membered Ir-S-C-S backbones led to significantly more acute S-Ir-S bite angles $\left(71.35(5)^{\circ}\right.$ for Ir-2, $71.62(4)^{\circ}$ for Ir-3) than those of the larger five- or six-membered heterocycles [13,27-29]. The Ir-S bond lengths (2.4486(17)-2.4643(12) $\AA$ ) in an ancillary ligand were significantly longer than the Ir-C bond lengths (2.000(4)-2.020(5) $\AA$ ) and the Ir-N bonds lengths (2.037(4)-2.053(4) $\AA$ ) in cyclometalated ligands. All other bond lengths and angles were within the normal values.

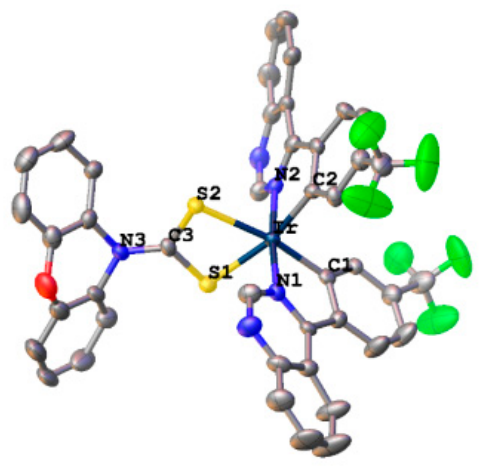

(a)

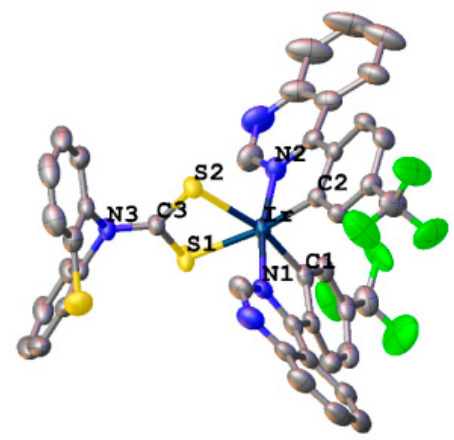

(b)

Figure 1. ORTEP diagrams of (a) Ir-2 (CCDC no. 2065084) and (b) Ir-3 (CCDC no. 2065079) with the atom-numbering schemes. Hydrogen atoms are omitted for clarity.

Thermogravimetric analysis (TGA) measurements were carried out to investigate the thermal properties of these three $\operatorname{Ir}(\mathrm{III})$ complexes because the thermal stability of the emitters is vital for stable OLEDs. As shown in Figure $\mathrm{S} 1$ and Table 1, the decomposition temperatures $\left(T_{\mathrm{d}}, 5 \%\right.$ weight loss) of these $\operatorname{Ir}(\mathrm{III})$ complexes were 329,343 , and $375^{\circ} \mathrm{C}$ for Ir-1, Ir-2, and Ir-3, respectively, indicating that all complexes had good thermal stability.

Table 1. Physical and photophysical properties of the three complexes.

\begin{tabular}{|c|c|c|c|c|c|c|}
\hline Complex & $\begin{array}{l}T_{\mathrm{d}}{ }^{\mathrm{a}} \\
\left({ }^{\circ} \mathrm{C}\right)\end{array}$ & $\begin{array}{l}\text { Absorption }{ }^{b} \\
(\lambda, \mathrm{nm})\end{array}$ & $\begin{array}{l}\text { Emission }^{b} \\
\left(\lambda_{\max }, \mathrm{nm}\right)\end{array}$ & $\begin{array}{c}\tau_{298 \mathrm{~K}}{ }^{\mathrm{c}} \\
(\mu \mathrm{s})\end{array}$ & $\begin{array}{l}\Phi_{P}{ }^{c} \\
(\%)\end{array}$ & $\begin{array}{c}\text { HOMO/LUMO }_{(\mathrm{eV})}^{\mathrm{d}} \\
\end{array}$ \\
\hline Ir-1 & 329 & $326 / 437$ & 622 & 0.45 & 35.4 & $-5.67 /-3.55$ \\
\hline Ir-2 & 343 & $341 / 433$ & 619 & 0.46 & 50.4 & $-5.57 /-3.54$ \\
\hline Ir-3 & 375 & $328 / 437$ & 622 & 0.59 & 52.8 & $-5.57 /-3.56$ \\
\hline
\end{tabular}

${ }^{a}$ Decomposition temperature. ${ }^{\mathrm{b}}$ Measured in DCM $\left(10^{-5} \mathrm{M}\right)$ at $298 \mathrm{~K} \cdot{ }^{\mathrm{c}}$ Measured in DCM $\left(10^{-5} \mathrm{M}\right)$ in a $\mathrm{N}_{2}$ atmosphere. ${ }^{\mathrm{d}}$ HOMO energy levels calculated from cyclic voltammetry analysis. LUMO energy levels calculated from cyclic voltammetry analysis and UV-Vis onset.

\subsection{Photophysical Property}

The ultraviolet-visible absorption and PL spectra of Ir-1, Ir-2, and Ir-3 recorded in dichloromethane solutions $\left(10^{-5} \mathrm{M}\right)$ at room temperature are shown in Figure 2 , and the pertinent data are displayed in Table 1. The 3D correlation spectra of excitation and emission spectra of three complexes are illustrated in Figure S2. The intense absorption bands of the three complexes below $390 \mathrm{~nm}$ were attributed to spin-allowed $\pi-\pi^{*}$ transitions related to the ligands and the relatively weaker absorption parts in the region of 390-515 nm were assigned to ${ }^{1}$ MLCT. The lowest-lying absorption from 515 to $630 \mathrm{~nm}$ were ascribed to spin-forbidden ${ }^{3} \mathrm{MLCT}$ and ${ }^{3} \mathrm{LC}$ due to the strong spin-orbit coupling of the iridium atom $[7,10,30]$. 


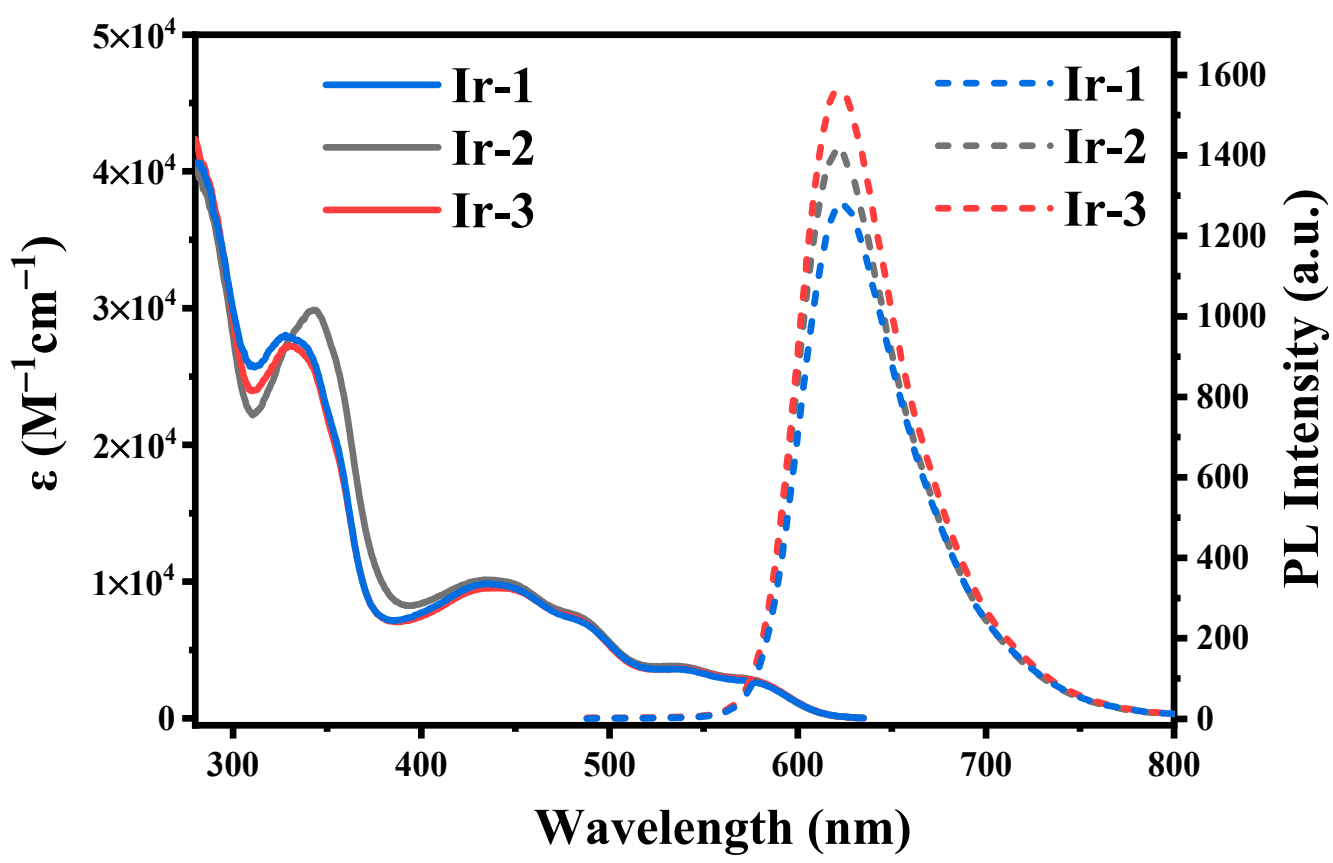

Figure 2. UV-vis absorption and PL spectra at $298 \mathrm{~K}$ of Ir-1, Ir-2, and Ir-3 complexes in dichloromethane (concentration: $10^{-5} \mathrm{M}$ ).

Three Ir(III) complexes exhibited approximative red emission peaks with the maximum at 622,619 , and $622 \mathrm{~nm}$ for Ir-1, Ir-2, and Ir-3, respectively. The PL spectra measured at $298 \mathrm{~K}$ were broad and featureless, and those measured at $77 \mathrm{~K}$ (Figure S3) also did not show fine vibronic progressions, perhaps indicating the main emissions of these complexes were likely dominated by the ${ }^{3}$ MLCT [31,32]. The PL quantum yields of the three $\operatorname{Ir}(\mathrm{III})$ complexes were measured in degassed dichloromethane as $35.4 \%, 50.4 \%$, and $52.8 \%$, respectively (Table 1 and Figure S4), which were consist with their PL intensity sequence (Figure 2). As is known, the longer phosphorescent lifetime $(\tau)$ of the materials usually leads to a severer TTA both in PL and electroluminescence (EL), so materials with short $\tau$ values are favorable for fabrication of efficient OLEDs with low efficiency roll-off [33]. In this case, the three $\operatorname{Ir}(\mathrm{III})$ complexes showed relatively short $\tau$ values of $0.45,0.46$, and $0.59 \mu$ s (Table 1 and Figure S5), which was expected to increase spin-state mixing and delay the EL efficiency roll-off [34].

\subsection{Electrochemical Property and Theoretical Calculation}

The characteristics of frontier orbitals and the resulting highest occupied molecular orbital (HOMO) and the lowest unoccupied molecular orbital (LUMO) energy levels $\left(E_{\mathrm{HOMO}} / E_{\mathrm{LUMO}}\right)$ are important to the electrochemical property of $\operatorname{Ir}(\mathrm{III})$ complexes, which can provide a theoretical basis for the design and fabrication of OLEDs [35]. Cyclic voltammetry $(\mathrm{CV})$ measurements in deaerated $\mathrm{CH}_{3} \mathrm{CN}$ employing ferrocenium / ferrocene $\left(\mathrm{Fc}^{+} / \mathrm{Fc}\right)$ as the internal standard were carried out to study the redox properties and $\mathrm{HOMO} / \mathrm{LUMO}$ levels of all $\mathrm{Ir}(\mathrm{III})$ complexes (Figure S6). However, the reduction behaviors of $\operatorname{Ir}(\mathrm{III}) \mathrm{com}$ plexes were irreversible, so we were unable to estimate their HOMO and LUMO energies accurately [36]. According to the equations $E_{\mathrm{HOMO}}=-\left(E_{\mathrm{Ox}}-E_{\mathrm{Fc} / \mathrm{Fc}}{ }^{+}+4.8\right) \mathrm{eV}, E_{\mathrm{gap}}=$ $1240 / \lambda_{\text {abs-onset }}$, and $E_{\mathrm{LUMO}}=E_{\mathrm{HOMO}}+E_{\text {gap }}$, the HOMO levels for $\operatorname{Ir}(\mathrm{III})$ complexes were estimated on the basis of an oxidation potential of $4.8 \mathrm{eV}$ (below vacuum level) for $\mathrm{Fc}^{+} / \mathrm{Fc}$, the LUMO levels were estimated on the sum of HOMO levels, and the energy band gap was determined by absorption edge (MLCT) in the absorption spectrum [20,37,38]. The ${ }^{3}$ MLCT absorption bands of the three iridium complexes reached the absorption edge and thus mainly participated in the electron semiconductivity [39], which was in agreement with the calculation results of the frontier molecular orbital distributions and energy splitting of singlet and triplet states of Ir-3 (Table S3). All complexes had similar $E_{\mathrm{HOMO}}$ and $E_{\mathrm{LUMO}}$ 
values $(-5.67 /-3.55,-5.57 /-3.54$, and $-5.57 /-3.56 \mathrm{eV}$, Table 1$)$, which can be attributed to their similar structures.

To gain further insight into the electronic properties of the three complexes, density functional theory (DFT) calculations utilizing the Gaussian09 software were performed and the theoretical HOMO/LUMO orbital distributions of Ir-1, Ir-2, and Ir-3 are listed in Figure 3. The corresponding HOMO and LUMO electron cloud density distributions of each fragment of the $\operatorname{Ir}(\mathrm{III})$ complexes are listed in Table S4, which reveals that the HOMO and LUMO levels of Ir-1, Ir-2, and Ir-3 had almost identical distributions in iridium atoms, main ligands, and ancillary ligands. As shown in Figure 3 and Table S4, the HOMO orbitals of the $\operatorname{Ir}(\mathrm{III})$ complexes were mostly located on the main ligand (47.2-52.1\%) together with the d-orbitals of the iridium atoms (36.7-40.0\%) with a small portion of the ancillary ligands (10.8-12.8\%). The LUMO orbitals were mostly distributed over the $\pi^{*}$ orbitals of the main ligands $(94.7-95.1 \%)$ and a small extent on the d-orbitals of the iridium (2.7-3.9\%) and ancillary ligands (1.3-2.6\%). These results suggest that the ancillary ligands contributed much less in HOMO and LUMO distributions than the main ligands, so the difference of ancillary ligands had little impact on the photophysical properties of the three $\operatorname{Ir}(\mathrm{III})$ complexes.

HOMO
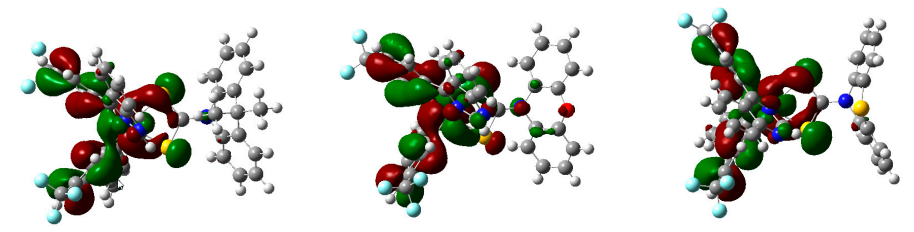

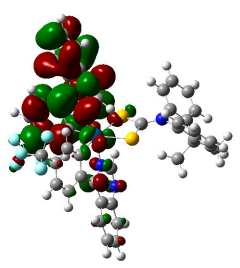

Ir-1

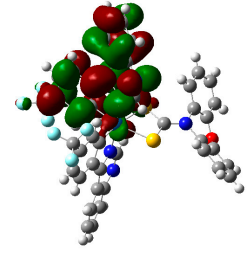

Ir-2

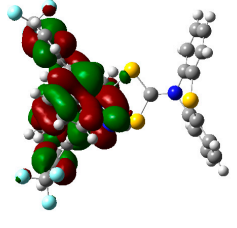

Ir-3

Figure 3. Theoretical HOMO and LUMO orbital electron cloud distributions of the three $\operatorname{Ir}(\mathrm{III})$ complexes.

\subsection{OLED Performance}

To illustrate the EL properties of these complexes, the single emitting layer (EML) devices named D1, D2, and D3 using Ir-1, Ir-2, and Ir-3 as emitters, respectively, were fabricated with the configuration of ITO (indium tin oxide)/HAT-CN (dipyrazino[2,3-f, $2^{\prime}, 3^{\prime}$ h] quinoxaline-2,3,6,7,10,11-hexacarbonitrile, $5 \mathrm{~nm}) /$ TAPC $\left(4,4^{\prime}\right.$-cyclohexylidenebis[ $N, N$ bis-(4-methylphenyl)aniline], $40 \mathrm{~nm}$ )/TCTA (4,4", $4^{\prime \prime}$-tris(carbazol-9-yl)triphenylamine, $10 \mathrm{~nm}$ )/Ir(III) complex (10 wt\%): 2,6DCzPPy (2,6-bis-(3-(carbazol-9-yl)phenyl)pyridine, $10 \mathrm{~nm}$ )/TmPyPB (1,3,5-tri(mpyrid-3-yl-phenyl)benzene, $50 \mathrm{~nm}) / \mathrm{LiF}(1 \mathrm{~nm}) / \mathrm{Al}$ (100 nm). As shown in Scheme 2, the HAT-CN, LiF, TAPC, and TmPyPB materials served as holeinjecting, electron-injecting, hole-transport, and electron-transport interface modified materials, respectively. The TCTA material also served as an electron-blocking layer material. The proper HOMO and LUMO energy levels of TCTA can not only match the adjacent carrier transport materials to reduce carrier injection and transport barriers, but also lower driving voltage. To reduce the TTA effect and prevent exciton diffusion and quenching in the adjacent layers of materials in OLEDs, the Ir(III) complexes have to be dispersed into the suitable host matrix [4,40]. Moreover, considering energy level matching in the 
host-guest system, the bipolar material 2,6DCzPPy with good and balance carrier transport proper acts as the host material for doping concentrations of Ir(III) emitters so that energy can transfer efficiently in the emitting layer (EML). The overall electroluminescence performances are shown in Figure 4 and Table 2.

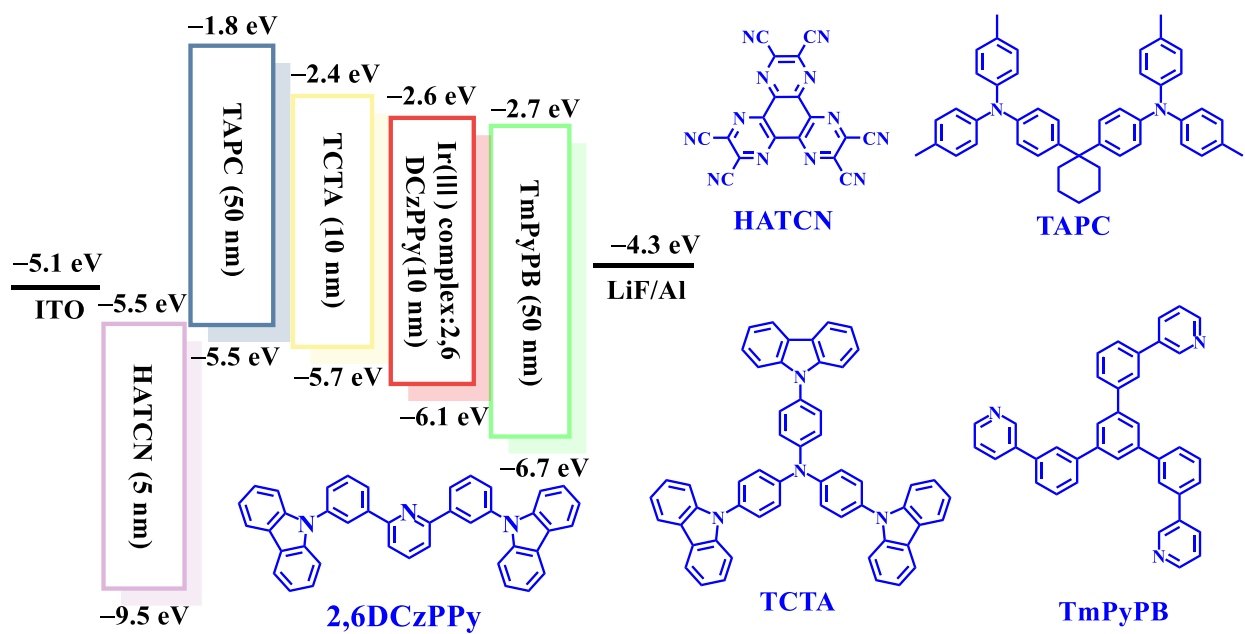

Scheme 2. Energy level diagram of the HOMO and LUMO levels of materials investigated and their chemical molecular structures.
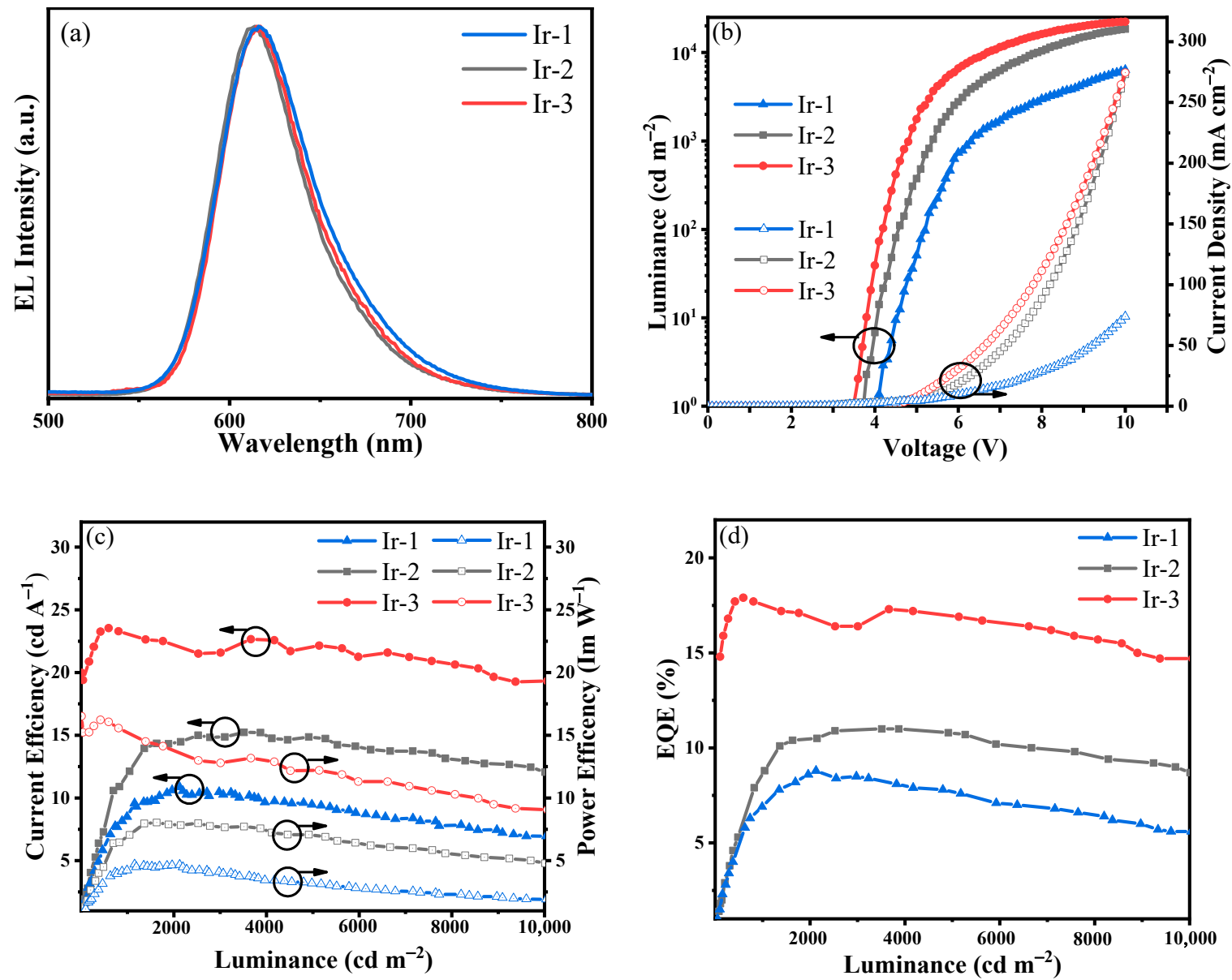

Figure 4. Electroluminescence performances of D1, D2, and D3: (a) electroluminescence spectra measured in 6 V, (b) current density-voltage curves and luminance-voltage curves, (c) current efficiency-luminance curves and power efficiencyluminance curves, and (d) EQE-luminance curves. 
Table 2. The key EL data of devices D1-D3.

\begin{tabular}{|c|c|c|c|c|c|c|}
\hline Device & $\begin{array}{c}V_{\text {turn-on }}{ }^{a} \\
(\mathrm{~V})\end{array}$ & $\begin{array}{c}L_{\max } b \\
{\left[\mathrm{~cd} \mathrm{~m}^{-2}(\mathrm{~V})\right]}\end{array}$ & $\begin{array}{c}\eta_{c, \max }{ }^{c} \\
{\left[\mathrm{~cd} \mathrm{~A} \mathrm{~A}^{-1}(\mathrm{~V})\right]}\end{array}$ & $\begin{array}{c}\eta_{p, \max }{ }^{d} \\
{\left[\operatorname{lm} W^{-1}(V)\right]}\end{array}$ & $\mathrm{EQE}_{\max } \mathrm{e}(\%)$ & $\begin{array}{l}\text { CIE } \\
(x, y)\end{array}$ \\
\hline D1 & 4.1 & $14,080(13.3)$ & $10.86(7.3)$ & $4.70(6.4)$ & 8.8 & $(0.62,0.34)$ \\
\hline D2 & 3.8 & $18,740(10.3)$ & $15.23(6.2)$ & $8.04(5.6)$ & 11.0 & $(0.64,0.35)$ \\
\hline D3 & 3.5 & $22,480(10.2)$ & 23.71(5.1) & $16.23(4.5)$ & 18.1 & $(0.63,0.35)$ \\
\hline
\end{tabular}

${ }^{\mathrm{a}}$ Turn-on voltage at $1 \mathrm{~cd} \mathrm{~m}^{-2} \cdot{ }^{\mathrm{b}}$ Maximum luminance. ${ }^{\mathrm{c}}$ Maximum current efficiency. ${ }^{\mathrm{d}}$ Maximum power efficiency. ${ }^{\mathrm{e}}$ Maximum external quantum efficiency calculated within visible spectrum region.

The EL emission peaks of the D1, D2, and D3 devices were 612, 613, and $619 \mathrm{~nm}$, with CIE coordinates at $(0.62,0.34),(0.64,0.35)$, and $(0.63,0.35)$, respectively, which were very close to those measured in $\mathrm{CH}_{2} \mathrm{Cl}_{2}$ solutions, indicating that the $\mathrm{EL}$ emissions of the devices originated from the $\operatorname{Ir}(\mathrm{III})$ complexes. No obvious host material emissions were observed in the three devices, suggesting that the energy transferred efficiently from the host material to the $\operatorname{Ir}(\mathrm{III})$ complexes in EML.

Owing to the same main ligand and similar ancillary ligand structures of the three Ir(III) complexes, the device performances mainly depended on their PL efficiencies. Respectively, device D1, employing Ir-1 $\left(\Phi_{\mathrm{P}}\right.$ is $\left.35.4 \%\right)$, showed the lowest EL performance, with a maximum luminance $\left(L_{\max }\right)$ of $14,080 \mathrm{~cd} \mathrm{~A}^{-1}$, a $\eta_{\mathrm{c}, \max }$ of $10.86 \mathrm{~cd} \mathrm{~A}^{-1}$, a maximum power efficiency $\left(\eta_{\mathrm{p}, \max }\right)$ of $4.70 \mathrm{~lm} \mathrm{~W}^{-1}$, and an $\mathrm{EQE}_{\max }$ of $8.8 \%$. Comparatively, device D2, based on Ir-2 ( $\Phi_{\mathrm{P}}$ is $\left.50.4 \%\right)$, exhibited better characteristics, with an $L_{\max }, \eta_{\mathrm{c}, \max }, \eta_{\mathrm{p}, \max }$, and $\mathrm{EQE}_{\max }$ of $18,740 \mathrm{~cd} \mathrm{~m}^{-2}, 15.23 \mathrm{~cd} \mathrm{~A}^{-1}, 8.04 \mathrm{~lm} \mathrm{~W}^{-1}$, and $11.0 \%$, respectively. Due to the highest $\Phi_{\mathrm{P}}$ of Ir-3 (52.8\%), device D3 achieved the best EL performance, with an $L_{\max }$ of $22,480 \mathrm{~cd} \mathrm{~m}^{-2}$, an $\eta_{c, \text { max }}$ of $23.71 \mathrm{~cd} \mathrm{~A}^{-1}$, an $\eta_{\mathrm{p} \text {,max }}$ of $16.23 \mathrm{~lm} \mathrm{~W}^{-1}$, $\mathrm{n}$ and an $\mathrm{EQE}_{\max }$ of $18.1 \%$, respectively.

Summarized from the investigated results, all devices achieved good OLED properties. The possible reasons were summarized as follows: Firstly, different electron-donating moieties in dithiocarbamate derivatives and the nitrogen frame of cyclometalated ligand equipped the Ir(III) complexes with bipolar properties, which may have helped to widen the recombination area and balance distribution for the excitons. Secondly, the sulfur atom had strong coordination capability with the iridium atom so they could form stable dithiolate compounds that could reduce the work function of the emitter and the threshold electric field [20]. Lastly, the bulky nonplanar butterfly conformation of the ancillary ligands sufficiently inhibited molecular aggregation and the formation of intermolecular excimers, consequently reducing the intermolecular interactions [8]. Compared to the previously reported Ir(III) complexes with sulfur-containing four-membered ancillary ligands (Table S5), the performances of the three Ir(III) complexes were not excellent due to the moderate PLQYs of three emitters.

\section{Experimental Section}

\subsection{General Procedures}

All reagents and chemicals were purchased from commercial sources and used without further purification. ${ }^{1} \mathrm{H}$ NMR, ${ }^{13} \mathrm{C}$ NMR and ${ }^{19} \mathrm{~F}$ NMR spectra were measured on a Bruker AM 400 spectrometer (Bruker, Karlsruhe, Germany). High-resolution electrospray mass spectra (HR-MS) were measured on a MTQ III q-TOF (Bruker, Karlsruhe, Germany). Absorption and photoluminescence spectra were measured on a UV-3100 spectrophotometer (Shimadzu, Kyoto, Japan) and a Hitachi F-4600 photoluminescence spectrophotometer (Hitachi, Kyoto, Japan), respectively. TG-DSC measurements were carried out on a TG sf/1100 (Mettler Toledo, Zurich, Switzerland). Cyclic voltammetry measurements were conducted on a MPI-A multifunctional electrochemical and chemiluminescent system ( $\mathrm{CH}$ Instruments, TX, USA) at room temperature with a polished Pt plate as the working electrode, a platinum thread as the counter electrode and a $\mathrm{Ag}-\mathrm{AgNO}_{3}(0.1 \mathrm{M})$ in $\mathrm{CH}_{3} \mathrm{CN}$ as the reference electrode, tetra-nbutylammonium perchlorate $(0.1 \mathrm{M})$ was used as the supporting electrolyte, using $\mathrm{Fc}^{+} / \mathrm{Fc}$ as the internal standard, the scan rate was $0.1 \mathrm{~V} / \mathrm{s}$. The absolute photoluminescence quantum yields and the decay lifetimes of the compounds 
were measured with HORIBA FL-3 fluorescence spectrometer(HORIBA, Kyoto, Japan). Thermogravimetric analysis (TGA) was performed on a TG sf/1100 under nitrogen at a heating rate of $10^{\circ} \mathrm{C} \mathrm{min}^{-1}$.

\subsection{Synthesis of Ligands and Complexes}

\subsubsection{Synthesis of the Main Ligand and $\left[\left(\mathrm{C}^{\wedge} \mathrm{N}\right)_{2} \operatorname{Ir}(\mu-\mathrm{Cl})\right]_{2}$ Chloride-Bridged Dimer}

4-Chloro-quinazoline $(6 \mathrm{mmol}), 4$-(trifluoromethyl)phenylboronic acid $(5 \mathrm{mmol})$, $\mathrm{Na}_{2} \mathrm{CO}_{3}(10 \mathrm{mmol})$, and $\mathrm{Pd}\left(\mathrm{PPh}_{3}\right)_{4}(0.1 \mathrm{mmol})$ were added to $40 \mathrm{~mL} \mathrm{THF} / \mathrm{H}_{2} \mathrm{O}(3: 1$, $v / v$ ) and the mixture was refluxed at $75{ }^{\circ} \mathrm{C}$ for $12 \mathrm{~h}$. The organic phase was extracted with $\mathrm{CH}_{2} \mathrm{Cl}_{2}$ and purified by silica gel column chromatography $\left(\mathrm{CH}_{2} \mathrm{Cl}_{2}\right.$ / petroleum ether $1: 2$ $(v / v))$. A total of $1.24 \mathrm{~g}$ main ligand $4 \mathrm{tfmpq}$ as white powder was obtained with a yield of $75.6 \%$.

$\mathrm{IrCl}_{3}(2.14 \mathrm{mmol})$ and $4 \mathrm{tfmpq}(5.14 \mathrm{mmol})$ were added to a 2-ethoxyethanol and water mixture. Then the solution was heated at $110{ }^{\circ} \mathrm{C}$ for $12 \mathrm{~h}$. After the addition of water, the precipitated red powder of $\left[(4 \mathrm{tfmpq})_{2} \operatorname{Ir}(\mu-\mathrm{Cl})\right]_{2}$ chloride-bridged dimer was filtered, washed, and dried in vacuum with a yield of $84.7 \%(2.8 \mathrm{~g})$.

\subsubsection{General Synthesis of the Ancillary Ligands and Ir(III) Complexes}

$\mathrm{NaH}(2.2 \mathrm{mmol})$ was added to a $10 \mathrm{~mL}$ ultra-dry tetrahydrofuran solution of 9,10dihydro-9,9-dimethylacridine, phenoxazine, or phenothiazine $(2 \mathrm{mmol})$ in an ice-water bath under an $\mathrm{N}_{2}$ atmosphere. After stirring for $1 \mathrm{~h}$ at room temperature, $\mathrm{CS}_{2}(2.2 \mathrm{mmol})$ was added to the system and the solution was stirred for another $2 \mathrm{~h}$. The sodium thionocarboxylate aqueous solutions were used in the next procedure without further purification.

\subsubsection{General Synthesis of the $\operatorname{Ir}(\mathrm{III})$ Complexes}

The $\left[(4 \mathrm{tfmpq})_{2} \operatorname{Ir}(\mu-\mathrm{Cl})\right]_{2}$ dimer $(0.83 \mathrm{mmol})$ was added to the sodium thionocarboxylate aqueous solutions and reacted for $5 \mathrm{~min}$ at room temperature. Then the solutions were concentrated and the resulting residues were purified by silica gel column chromatography $\left(\mathrm{CH}_{2} \mathrm{Cl}_{2}\right.$ /petroleum ether 2:1 $\left.(\mathrm{v} / \mathrm{v})\right)$ to obtain the final $\mathrm{Ir}(\mathrm{III})$ complexes.

Ir-1. Yield: $62.7 \% .{ }^{1} \mathrm{H}$ NMR $\left(400 \mathrm{MHz}, \mathrm{CDCl}_{3}\right) \delta 10.26(\mathrm{~s}, 2 \mathrm{H}), 8.81(\mathrm{~s}, 2 \mathrm{H}), 8.40$. $(\mathrm{d}, J=6.6 \mathrm{~Hz}, 2 \mathrm{H}), 8.26(\mathrm{~s}, 2 \mathrm{H}), 8.08-7.71(\mathrm{~m}, 6 \mathrm{H}), 7.45(\mathrm{~s}, 2 \mathrm{H}), 7.22(\mathrm{~d}, J=6.8 \mathrm{~Hz}, 2 \mathrm{H}), 7.18$ $(\mathrm{s}, 2 \mathrm{H}), 7.16(\mathrm{~s}, 2 \mathrm{H}), 6.75(\mathrm{~s}, 2 \mathrm{H}), 1.81(\mathrm{~s}, 2 \mathrm{H}), 1.61(\mathrm{~s}, 2 \mathrm{H}), 1.35(\mathrm{~s}, 2 \mathrm{H}) .{ }^{13} \mathrm{C}$ NMR $(101 \mathrm{MHz}$, $\left.\mathrm{CDCl}_{3}\right) \delta 213.24,173.23,162.18,154.17,149.42,145.91,141.18,136.97,133.63,130.76,130.33$, 130.02, 128.23, 127.97-127.30 (m), 126.34, 125.22, 124.77, 124.34, 123.05, 117.61-116.90 (m), 37.32. HR-MS Calculated: 1024.1549 for $\mathrm{C}_{46} \mathrm{H}_{30} \mathrm{~F}_{6} \mathrm{IrN}_{5} \mathrm{~S}_{2}[\mathrm{M}+\mathrm{H}]^{+}$, found: 1024.1551.

Ir-2. Yield: $48.9 \% .{ }^{1} \mathrm{H}$ NMR $\left(400 \mathrm{MHz}, \mathrm{CDCl}_{3}\right) \delta 10.26(\mathrm{~s}, 2 \mathrm{H}), 8.82(\mathrm{~d}, J=8.5 \mathrm{~Hz}, 2 \mathrm{H})$ $8.41(\mathrm{~d}, J=8.4 \mathrm{~Hz}, 2 \mathrm{H}), 8.28(\mathrm{~d}, J=8.2 \mathrm{~Hz}, 2 \mathrm{H}), 8.04-7.98(\mathrm{~m}, 2 \mathrm{H}), 7.94(\mathrm{~d}, J=7.7 \mathrm{~Hz}, 2 \mathrm{H})$, 7.88-7.82 (m, 2H), 7.25-7.16 (m, 6H), 7.05 (ddd, $J=8.6,6.6,2.2 \mathrm{~Hz}, 2 \mathrm{H}), 6.71(\mathrm{~s}, 2 \mathrm{H}) .13 \mathrm{C}$ $\operatorname{NMR}\left(101 \mathrm{MHz}, \mathrm{CDCl}_{3}\right) \delta 215.89,174.25,162.74,155.15,150.46(\mathrm{~d}, J=4.6 \mathrm{~Hz}), 146.89,134.80$, $131.82,131.50,131.19,129.32,129.10-128.98(\mathrm{~m}), 128.98-128.17(\mathrm{~m}), 128.15(\mathrm{~d}, J=2.3 \mathrm{~Hz})$, $126.03,125.77,124.76,122.49,121.89,118.37$ (dd, $J=7.0,3.5 \mathrm{~Hz}$ ), 117.65. HR-MS Calculated: 998.1029 for $\mathrm{C}_{43} \mathrm{H}_{24} \mathrm{~F}_{6} \mathrm{IrN}_{5} \mathrm{OS}_{2}[\mathrm{M}+\mathrm{H}]^{+}$, found: 998.1026 .

Ir-3. Yield: $85.5 \% .{ }^{1} \mathrm{H}$ NMR (400 MHz, $\left.\mathrm{CDCl}_{3}\right) 10.51(\mathrm{~s}, 1 \mathrm{H}), 9.96(\mathrm{~s}, 1 \mathrm{H}), 8.81(\mathrm{~m}$, $2 \mathrm{H}), 8.34(\mathrm{~m}, 4 \mathrm{H}), 8.13-7.71(\mathrm{~m}, 5 \mathrm{H}), 7.69-7.37(\mathrm{~m}, 3 \mathrm{H}), 7.23(\mathrm{~m}, 6 \mathrm{H}), 6.67(\mathrm{~m}, 2 \mathrm{H}) .{ }^{13} \mathrm{C}$ $\operatorname{NMR}\left(101 \mathrm{MHz}, \mathrm{CDCl}_{3}\right) \delta 216.8,174.2,150.5,146.9,137.6,134.7,132.9,131.7,131.3(\mathrm{q}$, $J=30.9 \mathrm{~Hz}), 129.3,128.8(\mathrm{~d}, J=3.1 \mathrm{~Hz}), 128.6(\mathrm{q}, J=4.0 \mathrm{~Hz}), 128.6,128.0(\mathrm{~d}, J=11.7 \mathrm{~Hz})$, 127.8, $126.3(\mathrm{~d}, J=4.6 \mathrm{~Hz}), 125.8,121.9,118.3(\mathrm{q}, J=3.9 \mathrm{~Hz})$. HR-MS Calculated: 1014.0800 for $\mathrm{C}_{43} \mathrm{H}_{24} \mathrm{~F}_{6} \mathrm{IrN}_{5} \mathrm{~S}_{3}[\mathrm{M}+\mathrm{H}]^{+}$, found: 1014.0800.

\subsection{OLED Fabrication and Measurement}

All OLEDs were fabricated on the pre-patterned ITO-coated glass substrate with a sheet resistance of $15 \Omega / \mathrm{sq}$. The deposition rate for the organic compounds was $1-2 \AA / \mathrm{s}$. The phosphor and the host 2,6DCzPPy were co-evaporated to form an emitting layer from two separate sources. The cathode consisting of $\mathrm{LiF} / \mathrm{Al}$ was deposited by evaporation 
of $\mathrm{LiF}$ with a deposition rate of $0.1 \AA / \mathrm{s}$ and then by evaporation of $\mathrm{Al}$ metal with a rate of $3 \AA / s$. The effective area of the emitting diode was $0.1 \mathrm{~cm}^{2}$. The thickness of each layer was calculated by the readings of crystal oscillators. The brightness of the device was recorded with a luminance meter (ST-86LA, Beijing Normal University Photoelectric Instrument Factory) and the current density was detected by Keithley 2400 (Tektronix Inc) with experimental uncertainties of about $5 \%$.

\section{Conclusions}

In summary, three red Ir(III) complexes, Ir-1, Ir-2, and Ir-3 with four-membered ring Ir-S-C-S structures were obtained rapidly at room temperature in $5 \mathrm{~min}$ with the nitrogen heterocycle $4 \mathrm{tfmpq}$ as the main ligand and different thionocarboxylates as the ancillary ligands. The diversity of the four-membered ring ligands was greatly enriched by employing different electron-donating groups 9,10-dihydro-9,9-dimethylacridine, phenoxazine, and phenothiazine in the ancillary ligands. Due to the same main ligand and similar ancillary ligand structures, the three Ir(III) complexes bore similar emission wavelengths at around $619 \mathrm{~nm}$ with phosphorescence quantum yields from $35.4 \%$ to $52.8 \%$ and short excited lifetimes lower than $1 \mu \mathrm{s}$. With the three complexes as dopants, all devices achieved good performances. However, the device using the Ir(III) complex with phenothiazine as an electron-donating group in the ancillary ligand displayed the best performances, with an $L_{\max }$ of $22,480 \mathrm{~cd} \mathrm{~m}^{-2}$, an $\eta_{\mathrm{c}, \max }$ of $23.71 \mathrm{~cd} \mathrm{~A}^{-1}$, and an EQE $\max$ of $18.1 \%$.

Supplementary Materials: The following are available online. Figure S1: The TG curve of the three Ir(III) complexes under nitrogen at a heating rate of $10^{\circ} \mathrm{C} \mathrm{min}^{-1}$; Figure S2: 3D excitation-emission correlation spectrums of Ir-1, Ir-2, and Ir-3; Figure S3: PL spectra at $77 \mathrm{~K}$ of Ir-1, Ir-2, and Ir-3 complexes in dichloromethane solutions $\left(10^{-5} \mathrm{M}\right)$; Figure S4: PLQY of Ir-1, Ir-2, and Ir-3 in degassed dichloromethane solution $\left(10^{-5} \mathrm{M}\right)$; Figure S5: The lifetime curves of Ir-1, Ir-2, and Ir-3 in degassed dichloromethane solution $\left(10^{-5} \mathrm{M}\right)$; Figure S6: CV curves of the Fc, Ir-1, Ir-2, and Ir-3 in deaerated $\mathrm{CH}_{3} \mathrm{CN}$ solution $\left(10^{-5} \mathrm{M}\right)$ Figure S7: ${ }^{1} \mathrm{H}$ NMR spectrum of Ir-1; Figure S8: ${ }^{1} \mathrm{H}$ NMR spectrum of Ir-2; Figure S9: ${ }^{1} \mathrm{H}$ NMR spectrum of Ir-3; Figure S10: ${ }^{13} \mathrm{C}$ NMR spectrum of Ir-1; Figure S11: ${ }^{13} \mathrm{C}$ NMR spectrum of Ir-2; Figure S12: ${ }^{13} \mathrm{C}$ NMR spectrum of Ir-3; Figure S13: ${ }^{19} \mathrm{~F}$ NMR spectrum of Ir-1; Figure S14: ${ }^{19} \mathrm{~F}$ NMR spectrum of Ir-2; Figure S15: ${ }^{19} \mathrm{~F}$ NMR spectrum of Ir-3; Table S1: The crystallographic data of Ir-2 and Ir-3; Table S2: Selected bond lengths and angles of Ir-2 and Ir-3; Table S3: Frontier molecular orbital distributions and energy splitting of singlet and triplet states of Ir-3; Table S4: HOMO and LUMO electron cloud density distributions of each fragment of all Ir(III) complexes; Table S5: The reported device performances with $\operatorname{Ir}(\mathrm{III})$ complexes based on sulfur-containing four-membered ancillary ligands.

Author Contributions: Conceptualization, Y.-X.Z. and M.-X.M.; methodology, M.-X.M., Y.S., Q.-M.L., and S.X.; software, X.-F.L., Z.-L.T., and X.-J.W.; validation, F.-L.L.; writing-original draft preparation, M.-X.M.; writing-review and editing, Y.-X.Z. All authors have read and agreed to the published version of the manuscript.

Funding: This research was funded by the National Natural Science Foundation of China (51773088, 21975119).

Institutional Review Board Statement: Not applicable.

Informed Consent Statement: Not applicable.

Data Availability Statement: The data presented in this study are available in supplementary material.

Conflicts of Interest: The authors declare no conflict of interest.

Sample Availability: Samples of the compounds are not available from the authors.

\section{References}

1. Xiao, L.X.; Chen, Z.J.; Qu, B.; Luo, J.X.; Kong, S.; Gong, Q.H.; Kido, J.J. Recent Progresses on Materials for Electrophosphorescent Organic Light-Emitting Devices. Adv. Mater. 2011, 23, 926-952. [CrossRef] [PubMed]

2. Yang, X.; Zhou, G.; Wong, W.Y. Functionalization of phosphorescent emitters and their host materials by main-group elements for phosphorescent organic light-emitting devices. Chem. Soc. Rev. 2015, 44, 8484-8575. [CrossRef] [PubMed] 
3. Han, H.B.; Cui, R.Z.; Jing, Y.M.; Lu, G.Z.; Zheng, Y.X.; Zhou, L.; Zuo, J.L.; Zhang, H. Highly efficient orange-red electroluminescence of iridium complexes with good electron mobility. J. Mater. Chem. C 2017, 5, 8150-8159. [CrossRef]

4. Tao, Y.T.; Yang, C.L.; Qin, J.G. Organic host materials for phosphorescent organic light-emitting diodes. Chem. Soc. Rev. 2011, 40, 2943-2970. [CrossRef] [PubMed]

5. Yang, C.H.; Cheng, Y.M.; Chi, Y.; Hsu, C.J.; Fang, F.C. Blue-Emitting Heteroleptic Iridium(III) Complexes Suitable for HighEfficiency Phosphorescent OLEDs. Angew. Chem. Int. Ed. 2006, 46, 2418-2421. [CrossRef]

6. Duan, J.P.; Sun, P.P.; Cheng, C.H. New Iridium Complexes as Highly Efficient Orange-Red Emitters in Organic Light-Emitting Diodes. Adv. Mater. 2003, 15, 224-228. [CrossRef]

7. Ma, D.X.; Zhang, C.; Qiu, Y.; Duan, L. Sublimable Cationic Iridium(III) Complexes with 1,10-Phenanthroline Derivatives as Ancillary Ligands for Highly Efficient and Polychromic Electroluminescence. Chem. Eur. J. 2016, 22, 15888-15895. [CrossRef]

8. Bodedla, G.B.; Thomas, K.R.J.; Kumar, S.; Jou, J.H.; Li, C.J. Phenothiazine-based bipolar green-emitters containing benzimidazole units: Synthesis, photophysical and electroluminescence properties. RSC Adv. 2015, 5, 87416-87428. [CrossRef]

9. Zhang, Q.; Wang, X.L.; Wang, X.; Wang, L.; Zhang, J.L. Computational studies of electronic structures and photophysical properties of luminescent iridium(III) complexes based on amidinate/bis(pyridylphenyl) ligands. Org. Electron. 2016, 33, 281-289. [CrossRef]

10. Lamansky, S.; Djurovich, P.; Murphy, D.; Abdel-Razzaq, F.; Thompson, M.E. Highly Phosphorescent Bis-Cyclometalated Iridium Complexes: Synthesis, Photophysical Characterization, and Use in Organic Light Emitting Diodes. J. Am. Chem. Soc. 2001, 123, 4304-4312. [CrossRef]

11. Cheung, W.M.; Lai, C.Y.; Zhang, Q.F.; Wong, W.Y.; Williams, I.D.; Leung, W.H. Iridium and rhodium complexes containing dichalcogenoimidodiphosphinato ligands. Polyhedron 2007, 359, 2712-2720. [CrossRef]

12. Su, N.; Zheng, Y.X. Four-membered red iridium(III) complexes with Ir-S-P-S structures: Rapid room-temperature synthesis and application in OLEDs. Dalton Trans. 2019, 48, 7583-7588. [CrossRef]

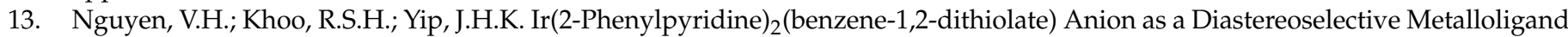
and Nucleophile: Stereoelectronic Effect, Spectroscopy, and Computational Study of the Methylated and Aurated Complexes and their Oxygenation Products. Inorg. Chem. 2015, 5, 2264-2277. [CrossRef]

14. Lau, M.K.; Cheung, K.M.; Zhang, Q.F.; Song, Y.; Wong, W.T.; Williams, D.; Leung, W.H. Iridium(III) and rhodium(III) cyclometalated complexes containing sulfur and selenium donor ligands. J. Organomet. Chem. 2004, 689, 2401-2410. [CrossRef]

15. Liang, X.; Zhang, F.; Yan, Z.P.; Wu, Z.G.; Zheng, Y.; Cheng, G.; Wang, Y.; Zuo, J.L.; Pan, Y.; Che, C.M. Fast Synthesis of Iridium(III) Complexes Incorporating a Bis(diphenylphorothioyl)amide Ligand for Efficient Pure Green OLEDs. ACS Appl. Mater. Interfaces 2019, 11, 7184-7191. [CrossRef]

16. Lu, G.Z.; Su, N.; Yang, H.; Zhu, Q.; Zhang, W.W.; Zheng, Y.; Zhou, L.; Zuo, J.L.; Chen, Z.X.; Zhang, H. Rapid room temperature synthesis of red iridium(III) complexes containing a four-membered Ir-S-C-S chelating ring for highly efficient OLEDs with EQE over 30\%. Chem. Sci. 2019, 10, 3535-3542. [CrossRef]

17. Chen, L.Q.; Yang, C.L.; Qin, J.G.; Jia, G.; Ma, D. Luminescent iridium(III) complexes with mixed 2-phenylpyridinato-C ${ }^{2}$,N and dithionate ligands for dopant emitter in OLEDs. Synth. Met. 2005, 152, 225-228. [CrossRef]

18. Chen, L.Q.; You, H.; Yang, C.L.; Zhang, X.W.; Qin, J.G.; Ma, D. Tuning the saturated red emission: Synthesis, electrochemistry and photophysics of 2-arylquinoline based iridium(III) complexes and their application in OLEDs. J. Mater. Chem. 2006, 16, 3332-3339. [CrossRef]

19. Chen, L.Q.; You, H.; Yang, C.L.; Ma, D.; Qin, J.G. Novel, highly efficient blue-emitting heteroleptic iridium(III) complexes based on fluorinated 1,3,4-oxadiazole: Tuning to blue by dithiolate ancillary ligands. Chem. Commun. 2007, 13, 1352-1354. [CrossRef]

20. Mei, Q.B.; Chen, C.; Tian, R.Q.; Yang, M.; Tong, B.H.; Hua, Q.F.; Shi, Y.J.; Fan, Q.L.; Ye, S.H. Highly Efficient Orange Phosphorescent Organic Light-Emitting Diodes Based on Iridium(III) Complex with Diethyldithiocarbamate (S`S) as the Ancillary Ligand. RSC Adv. 2016, 6, 64003-64008. [CrossRef]

21. Lu, G.Z.; Li, X.; Liu, L.; Zhou, L.; Zheng, Y.X.; Zhang, W.W.; Zuo, J.L.; Zhang, H. Correction: Efficient phosphorescent red iridium(III) complexes containing a four-membered Ir-S-C-S ring backbone and large hindered spacers for high-performance OLEDs. J. Mater. Chem. C 2019, 7, 3863-3868. [CrossRef]

22. Su, N.; Li, F.L.; Zheng, Y.X. Four-membered red iridium(III) complexes with Ir-S-C-S structures for efficient organic light-emitting diodes. J. Mater. Chem. C 2020, 8, 7411-7416. [CrossRef]

23. Padungros, P.; Wei, A. Practical Synthesis of Aromatic Dithiocarbamates. Synth. Commun. 2014, 44, 2336-2343. [CrossRef]

24. Yan, Z.P.; Liao, K.; Han, H.B.; Su, J.; Zheng, Y.X.; Zuo, J.L. Chiral iridium(III) complexes with four-membered Ir-S-P-S chelating rings for high-performance circularly polarized OLEDs. Chem. Commun. 2019, 55, 8215-8218. [CrossRef]

25. Song, Y.H.; Yeh, S.J.; Chen, C.T.; Chi, Y.; Liu, C.S.; Yu, J.K.; Hu, Y.H.; Chou, P.T.; Peng, S.M.; Lee, G.H. Bright and Efficient, Non-Doped, Phosphorescent Organic Red-Light-Emitting Diodes. Adv. Funct. Mater. 2010, 14, 1221-1226. [CrossRef]

26. Chen, L.Q.; Yang, C.L.; Qin, J.; Gao, J.; You, H.; Ma, D. Synthesis, structure, electrochemistry, photophysics and electroluminescence of 1,3,4-oxadiazole-based ortho-metalated iridium(III) complexes. J. Organomet. Chem. 2006, 691, 3519-3530. [CrossRef]

27. Na, H.; Teets, T.S. Highly Luminescent Cyclometalated Iridium Complexes Generated by Nucleophilic Addition to Coordinated Isocyanides. J. Am. Chem. Soc. 2018, 140, 6353-6360. [CrossRef]

28. Lai, P.N.; Brysacz, C.H.; Alam, M.K.; Ayoub, N.A.; Gray, T.G.; Bao, J.; Teets, T.S. Highly Efficient Red-Emitting Bis-Cyclometalated Iridium Complexes. J. Am. Chem. Soc. 2018, 140, 10198-10207. [CrossRef] 
29. Ma, X.F.; Xia, J.C.; Yan, Z.P.; Luo, X.F.; Wu, Z.G.; Zheng, Y.; Zhang, W.W. Highly efficient green and red electroluminescence with an extremely low efficiency roll-off based on iridium(III) complexes containing a bis(diphenylphorothioyl)amide ancillary ligand. J. Mater. Chem. C 2019, 7, 2570-2576. [CrossRef]

30. Yang, X.; Xu, X.; Dang, J.S.; Zhou, G.; Ho, C.L.; Wong, W.Y. From Mononuclear to Dinuclear Iridium(III) Complex: Effective Tuning of the Optoelectronic Characteristics for Organic Light-Emitting Diodes. Inorg. Chem. 2016, 55, 1720-1727. [CrossRef]

31. Luo, X.F.; Qu, Z.Z.; Han, H.B.; Su, J.; Yan, Z.P.; Zhang, X.M.; Tong, J.J.; Zheng, Y.X.; Zuo, J.L. Carbazole-Based Iridium(III) Complexes for Electrophosphorescence with EQE of 32.2\% and Low Efficiency Roll-Off. Adv. Opt. Mater. 2020, 9, $2001390-2001396$. [CrossRef]

32. Tsuboyama, A.; Iwawaki, H.; Furugori, M.; Mukaide, T.; Kamatani, J.; Igawa, S.; Moriyama, T.; Miura, S.; Takiguchi, T.; Oka $\mathrm{Da}, \mathrm{S}$. Homoleptic cyclometalated iridium complexes with highly efficient red phosphorescence and application to organic light-emitting diode. J. Am. Chem. Soc. 2003, 125, 12971-12979. [CrossRef]

33. Reineke, S.; Walzer, K.; Leo, K. Triplet-exciton quenching in organic phosphorescent light-emitting diodes with Ir-based emitters. Phys. Rev. B 2007, 75, 125328. [CrossRef]

34. Zhu, Y.C.; Zhou, L.; Li, H.Y.; Xu, Q.L.; Teng, M.Y.; Zheng, Y.X.; Zuo, J.L.; Zhang, H.J.; You, X.Z. Highly Efficient Green and Blue-Green Phosphorescent OLEDs Based on Iridium Complexes with the Tetraphenylimidodiphosphinate Ligand. Adv. Mater. 2011, 23, 4041-4046. [CrossRef]

35. Su, N.; Yang, H.Q.; Zheng, Y.X.; Chen, Z.X. Sulfur atom containing ligands induced rapid room temperature synthesis of red iridium(III) complexes with Ir-S-P-S structures for OLEDs. New J. Chem. 2019, 43, 8722-8727. [CrossRef]

36. Cho, M.J.; Jin, J.-I.; Choi, D.H.; Yoon, J.H.; Hong, C.S.; Kim, Y.M.; Park, Y.W.; Ju, B.-K. Tunable emission of polymer light emitting diodes bearing green-emitting Ir(III) complexes: The structural role of 9-((6-(4-fluorophenyl)pyridin-3-yl)methyl)-9H-carbazole ligands. Dyes Pigm. 2010, 85, 143-151. [CrossRef]

37. Zhang, Y.P.; Liang, X.; Luo, X.F.; Song, S.Q.; Pan, Y. Chiral Spiro-Axis Induced Blue Thermally Activated Delayed Fluorescence Material for Efficient Circularly Polarized OLEDs with Low Efficiency Roll-off. Angew. Chem. Int. Ed. 2021, 133, 8516-8521. [CrossRef]

38. Min, J.C.; Jin, J.I.; Dong, H.C.; Kim, Y.M.; Park, Y.W.; Ju, B.K. Phosphorescent, green-emitting Ir(III) complexes with carbazolylsubstituted 2-phenylpyridine ligands: Effect of binding mode of the carbazole group on photoluminescence and electrophosphorescence. Dyes Pigm. 2009, 83, 218-224.

39. Liu, Z.W.; Bian, Z.Q.; Feng, H.; Nie, D.B.; Fei, D.; Chen, Z.Q.; Huang, C.H. Highly efficient, orange-red organic light-emitting diodes using a series of green-emission iridium complexes as hosts. Org. Electron. 2009, 10, 247-255. [CrossRef]

40. Yeh, S.J.; Wu, M.F.; Chen, C.T.; Song, Y.H.; Chi, Y.; Ho, M.H.; Hsu, S.F.; Chen, C.H. New Dopant and Host Materials for Blue-Light-Emitting Phosphorescent Organic Electroluminescent Devices. Adv. Mater. 2005, 17, 285-289. [CrossRef] 